\title{
Safety Assessment of Etofenprox, S-Methoprene, and Piperonyl Butoxide in Dogs Topically Exposed to Bio Spot Defense
}

\section{Stephanie D Bland, Ramesh C Gupta*, Michelle A Lasher and Terry D Canerdy}

Toxicology Department, Breathitt Veterinary Center, Murray State University, Murray/Hopkinsville, KY, USA

\begin{abstract}
Use of ectoparasiticides on pets seems inevitable since pets are commonly infested with fleas, ticks, and many other external parasites. Currently, pyrethroids are more commonly used than any other class of ectoparasiticides because they are considered relatively safe. Due to paucity of data, serious concerns have been raised not only about their safety in dogs but their transferable residues to owners, veterinarians, veterinary technologists, and dog handlers who come in contact with treated dogs on a daily basis. The present investigation was therefore undertaken to determine the toxicity and safety of "Bio Spot Defense" applied to six adult dogs, and to determine the residue of active ingredients (etofenprox, s-methoprene, and piperonyl butoxide) in blood of dogs and cotton gloves worn for five minutes to pet dogs at $24,48,72$ hours, and 1, 2, 3, 4, and 5 weeks post-application. At these time intervals, dogs were evaluated for physical examination. Residues of active ingredients were confirmed and quantitated using GC/ MS. In the blood, etofenprox was detected as early as 48 hours $(18.42 \pm 5.05 \mu \mathrm{g} / \mathrm{g})$ and the residue persisted until 1 week $(0.80 \pm 0.35 \mu \mathrm{g} / \mathrm{g})$. S-methoprene and piperonyl butoxide were not detected in the blood. In the gloves, the highest concentrations of etofenprox, s-methoprene, and piperonyl butoxide were determined at 24 hours $(9,552.00$ $\pm 1551.83 ; 2,307.86 \pm 456.70$; and $1286.13 \pm 0.49 \mu \mathrm{g} / \mathrm{g}$, respectively). Residues of all three compounds were detected in appreciable concentrations in the gloves until 1 week $(294.86 \pm 27.22 ; 80.62 \pm 10.06$; and $40.49 \pm 5.78$ $\mu \mathrm{g} / \mathrm{g}$, correspondingly). Their residues persisted in insignificant amounts in gloves until 5 weeks. In conclusion, findings of this investigation suggest that Bio Spot Defense product appears to be safe for dogs and their owners, but the veterinary personnel can be exposed to significant levels of etofenprox, s-methoprene, and piperonyl butoxide following chronic exposure, if not properly protected.
\end{abstract}

Keywords: Etofenprox; S-methoprene; Piperonyl butoxide; Pyrethroids; Ectoparasiticide toxicity; Ectoparasiticide safety; Flea and tick killer; Bio spot defense

\section{Introduction}

Blood sucking ticks, fleas, mosquitoes, and other ectoparasites commonly infest dogs and pose a serious global health concern as they can transmit infectious diseases between humans and animals. The use of ectoparasiticides on pets therefore is not only imminent but seems inevitable. Currently, pyrethroids are more widely used than any other class of ectoparasiticides (organophosphates, carbamates, neonicotinoids, etc) because they are considered relatively safe due to their species selectivity $[1,2]$. Due to lack of safety data, serious concerns have been raised for their safe use in dogs and about transferable residues to the owners, veterinarians, veterinary technologists, and dog handlers who come in contact with these ectoparasiticides on a daily basis.

Bio Spot Defense Flea and Tick Spot On (hereafter referred to as Bio Spot Defense) is a relatively new over the counter topical ectoparasiticide for dogs, which kills and prevents ticks, fleas, and mosquitoes. The product consists of three active ingredients: 1 . Etofenprox (2-(4-ethoxyphenyl)-2-methylpropyl 3-phenoxybenzyl ether), 30.0\%; 2. S-methoprene (2E,4E)-11-methoxy-3,7,11trimethyl-2,4-dodecadienoic acid 1-methylethyl ester), 3.6\%; and 3. Piperonyl butoxide (5-[2-(2-butoxyethoxy)ethoxymethyl]-6-propyl1,3-benzodioxole), 5.0\% [3]. Chemical structures of etofenprox, s-methoprene, and piperonyl butoxide are shown in Figure 1.

According to the label, the product is effective against ticks (Ixodes spp.), mosquitoes (Anopheles quadrimaculatus), flea (Ctenocephalides spp.) eggs, flea larvae, and adult fleas for up to two and a half months, usually during the summer. Etofenprox is a rapidly acting pyrethroid insecticide, which can kill adult fleas and ticks on dogs as early as

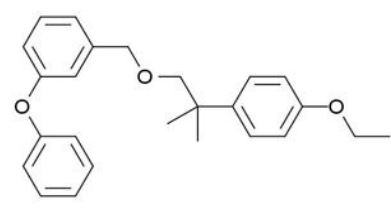

A. Etofenprox

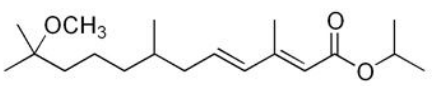

B. S-methoprene

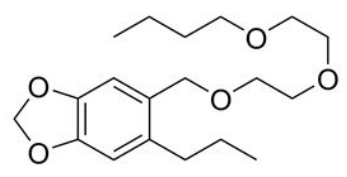

C. Piperonyl butoxide

Figure 1: Chemical structures of etofenprox, s-methoprene, and piperonylbutoxide.

*Corresponding author: Ramesh C Gupta, Professor and Head, Toxicology Department, Breathitt Veterinary Center, Murray State University, P.O. Box 2000; 715 North Drive, Hopkinsville, KY 42240-2000, USA, Tel: (270) 886-3959; Fax: (270) 886-4295; E-mail: rgupta@murraystate.edu

Received October 15, 2013; Accepted December 12, 2013; Published December 16,2013

Citation: Bland SD, Gupta RC, Lasher MA, Canerdy TD (2013) Safety Assessment of Etofenprox, S-Methoprene, and Piperonyl Butoxide in Dogs Topically Exposed to Bio Spot Defense. J Veterinar Sci Technol 4: 148. doi:10.4172/2157-7579.1000148

Copyright: $\odot 2013$ Bland SD, et al. This is an open-access article distributed under the terms of the Creative Commons Attribution License, which permits unrestricted use, distribution, and reproduction in any medium, provided the original author and source are credited. 
within 15 minutes of application [4]. Etofenprox is an insecticide with contact and systemic action, with applications in agriculture, public health and animal health. S-methoprene is an insect growth regulator due to its ovicidal and larvicidal actions; and piperonyl butoxide is a synergist, which enhances the persistence and effects of etofenprox and s-methoprene [5-7].

According to the Bio Spot Defense website, the possible side effects of this product include drowsiness, itching, redness or rashes, hair discoloration, and hair loss at the site of application [4]. There is a high confidence level about safety of Bio Spot Defense to the persons applying and to their pets due to a low acute mammalian toxicity of etofenprox, (s)-methoprene, and piperonyl butoxide; and minimal potential of residue transfer to humans once the product is dried, usually between 12-24 hours. Although the product label states that it is safe once dried, there have been concerns regarding transferrable residue to humans coming into contact with Bio Spot Defense treated dogs on a daily basis. The Environmental Protection Agency has deemed both etofenprox and (s)-methoprene "safe". According to section 408(b)(2)(A)(ii) of the Federal Food, Drug, and Cosmetic Act, "safe" is defined as "there is a reasonable certainty that no harm will result from aggregate exposure to the pesticide residue, including all anticipated dietary exposures and all other exposures for which there is reliable information."This does not include occupational hazard [8]. Currently, there is no reported data regarding the levels of etofenprox, (s)-methoprene, and piperonyl butoxide that humans may be exposed to from coming in contact with dogs treated with Bio Spot Defense. In previous studies, we reported transferable residues of fipronil, imidacloprid and selamectin to humans from dogs treated topically with Frontline ${ }^{\mathrm{TM}}$, Advantage, and Revolution ${ }^{\mathrm{TM}}$, respectively, using the glove sampling method for petting dogs and assessing transferrable residue [9-12]

The acute oral $\mathrm{LD}_{50}$ values for etofenprox, s-methoprene, and piperonyl butoxide in rats are reported to be $2880 \mathrm{mg} / \mathrm{kg}, 34500 \mathrm{mg} / \mathrm{kg}$, and $7500 \mathrm{mg} / \mathrm{kg}$, respectively. In dogs, the acute oral $\mathrm{LD}_{50}$ for racemic and s-methoprene is between 5000 to $10000 \mathrm{mg} / \mathrm{kg}$. Dermal $\mathrm{LD}_{50}$ values for etofenprox and piperonyl butoxide in rats are $2140 \mathrm{mg} / \mathrm{kg}$ and $7950 \mathrm{mg} / \mathrm{kg}$, respectively. The acute dermal $\mathrm{LD}_{50}$ for both racemic and s-methoprene in rabbits is $>2000 \mathrm{mg} / \mathrm{kg}$. These toxicity data suggest that insecticides, such as etofenprox and s-methoprene, and a synergist piperonyl butoxide, are of low mammalian toxicity [4,5,13-16].

The present investigation was undertaken to assess the toxicity and safety of etofenprox, s-methoprene and piperonyl butoxide in dogs, and possible exposure to owners and veterinary personnel after topical application on dogs of Bio Spot Defense.

\section{Materials and Methods}

\section{Animals}

Six mixed breed adult dogs (medium length hair), weighing between 30-40 pounds, were used in this investigation. The dogs were not treated with any ectoparasiticide for at least two months prior to this study.

\section{Chemicals}

Bio Spot Defense Flea \& Tick Spot Onं, having etofenprox, s-methoprene, and piperonyl butoxide, was purchased from Farnam Pet Products (Phoenix, AZ). Technical grade Etofenprox (99.0\%), s-methoprene (99.2\%), and piperonyl butoxide (97.5\%) were purchased from Chem Service (West Chester, PA). All other chemicals with highest purity were obtained from Fisher Scientific (Fair Lawn, NJ).

\section{Experimental design}

Ectoparasiticide application: Bio Spot Defense Flea \& Tick Spot On (Farnam Pet Products, Phoenix, AZ) in the amount of $4.44 \mathrm{~mL}$ (etofenprox, 30\%; s-methoprene, 3.6\%: and piperonyl butoxide, $5 \%$ ) was topically applied on each dog. The product was applied directly to the skin on the back (at three evenly spaced spots) starting at the shoulder blades and ending at the base of the tail.The Smart Shield ${ }^{m}$ applicator was used to apply the product without humans coming in direct contact with Bio Spot Defense [3]. Following application of the product, the active ingredients redistribute into the skin, with a high concentration going into the sebaceous glands. The sebaceous glands release the drug continuously in the sebum along with other natural oils and waxes. This allows the drug to coat the hair shaft and skin surface providing longlasting protection against fleas, ticks, and mosquitoes [4].

Physical Examination: Dogs topically treated with Bio Spot Defense were evaluated for physical parameters. At specified time intervals, dogs were examined for body weight, behavior, and skin reaction at the Bio Spot Defense application site.

Sample collection for pesticide residue analysis: Cotton gloves used for petting dogs were collected at $0,24,48,72$ hour, and 1, 2, 3, 4 , and 5 week intervals; and blood samples were collected at 0,24 , 48, 72 hours, and 1 and 2 week intervals, for pesticides (etofenprox, s-methoprene, and piperonyl butoxide) residue analysis.

Glove sampling included the wipe sampling method, which consisted of petting the dog forward and back along its back and sides for five minutes with a $100 \%$ cotton glove. After sampling, the glove was immediately placed in a labeled $800 \mathrm{~mL}$ glass jar and kept at room temperature until analyzed ( $<72-96$ hours). Blood samples were collected from the cephalic vein using a $6 \mathrm{~mL}$ syringe with a 22-gauge needle. At each time interval, approximately $5 \mathrm{~mL}$ blood was collected in an EDTA anticoagulant tube and kept in the refrigerator until analyzed.

Sample extraction: Dog blood and cotton glove samples were extracted in methylene chloride: petroleum ether (50:50, vol $/ \mathrm{vol}$ ). Extracts were passed through the sodium sulfate, evaporated to dryness overnight, and reconstituted in methylene chloride: petroleum ether just prior to GC/MS analysis.

GC/MS analysis: All three active ingredients present in Bio Spot Defense (etofenprox, s-methoprene, and piperonyl butoxide) were confirmed using an Agilent Gas Chromatograph (GC model 7990A)/ Mass Spectrometer (MS model 5975C) coupled with a computer, and their concentrations were expressed in terms of $\mu \mathrm{g} / \mathrm{g}$. The evaporated extract was reconstituted in an appropriate volume of extraction solvents (methylene chloride: petroleum ether) and passed through a Sep-Pak Cartridge (Waters Corp, Milford, MA). One $\mu \mathrm{L}$ of sample extract was injected into the GC. The column used was Ultra II Crosslinked with 5\% phenyl methyl siloxane coating and the following dimensions (capillary $25 \mathrm{~m} \times 0.52 \mu \mathrm{m}$ ), which was directly connected to the Mass Selective Detector via a heated transfer line. The carrier gas was ultrapure $(99.9999 \%)$ helium at a flow of $1 \mathrm{~mL} / \mathrm{min}$, and the injector temperature was $200^{\circ} \mathrm{C}$. The injector was operated in the splitless mode. A temperature program for the GC-oven was used comprising a starting temperature of $150^{\circ} \mathrm{C}$ for $1 \mathrm{~min}$, and then increased to a final temperature of $300^{\circ} \mathrm{C}$ in $20^{\circ} \mathrm{C} / \mathrm{min}$ increments. The final temperature was maintained for $5 \mathrm{~min}$. The total duration of the chromatography for each injection was $14 \mathrm{~min}$. The transfer line temperature was $280^{\circ} \mathrm{C}$, the source temperature was $230^{\circ} \mathrm{C}$. The instrument was operated in electron ionization mode, and the ion energy was $70 \mathrm{eV}$. Peaks of s-methoprene, piperonyl butoxide, and etofenprox were eluted at 6.524 
Citation: Bland SD, Gupta RC, Lasher MA, Canerdy TD (2013) Safety Assessment of Etofenprox, S-Methoprene, and Piperonyl Butoxide in Dogs Topically Exposed to Bio Spot Defense. J Veterinar Sci Technol 4: 148. doi:10.4172/2157-7579.1000148

Page 3 of 7

min, $7.967 \mathrm{~min}$, and $10.105 \mathrm{~min}$, respectively. Sensitivity of GC/MS for these compounds was in the range of ng, and limit of detection was in the range of low $\mu \mathrm{g} / \mathrm{g}$.

\section{Results}

A single application of Bio Spot Defense, having etofenprox, s-methoprene and piperonyl butoxide, caused no adverse effects in dogs at any time during the study period of five weeks. There was no significant change in body weight and no skin reaction at the site of insecticide application.

The present study simulated a model for ectoparasiticides' exposure to veterinary personnel from handling canine patients treated with Bio Spot Defense. Residues of etofenprox, s-methoprene, and piperonyl butoxide transferred from the canine coat were measured on cotton gloves at various intervals using GC/MS. Total Ion Chromatogram revealed that the peaks of s-methoprene, piperonyl butoxide, and etofenprox eluted at $6.524,7.967$, and $10.105 \mathrm{~min}$, respectively (Figure 2).

The concentrations of etofenprox, s-methoprene, and piperonyl butoxide present in the cotton gloves transferred from petting dogs at various time intervals are shown in Figures 3-5. The highest concentrations of all three pesticides were found at $24 \mathrm{hr}$ post Bio Spot Defense application $(9,552.00 \pm 1551.83 ; 2,307.86 \pm 456.70$; and $1286.13 \pm 0.49 \mu \mathrm{g} / \mathrm{g}$, respectively). Significant concentrations of etofenprox, s-methoprene, and piperonyl butoxide were found in the gloves until one week $(294.86 \pm 27.22 ; 80.62 \pm 10.06$; and $40.49 \pm 5.78$ $\mu \mathrm{g} / \mathrm{g}$, correspondingly).

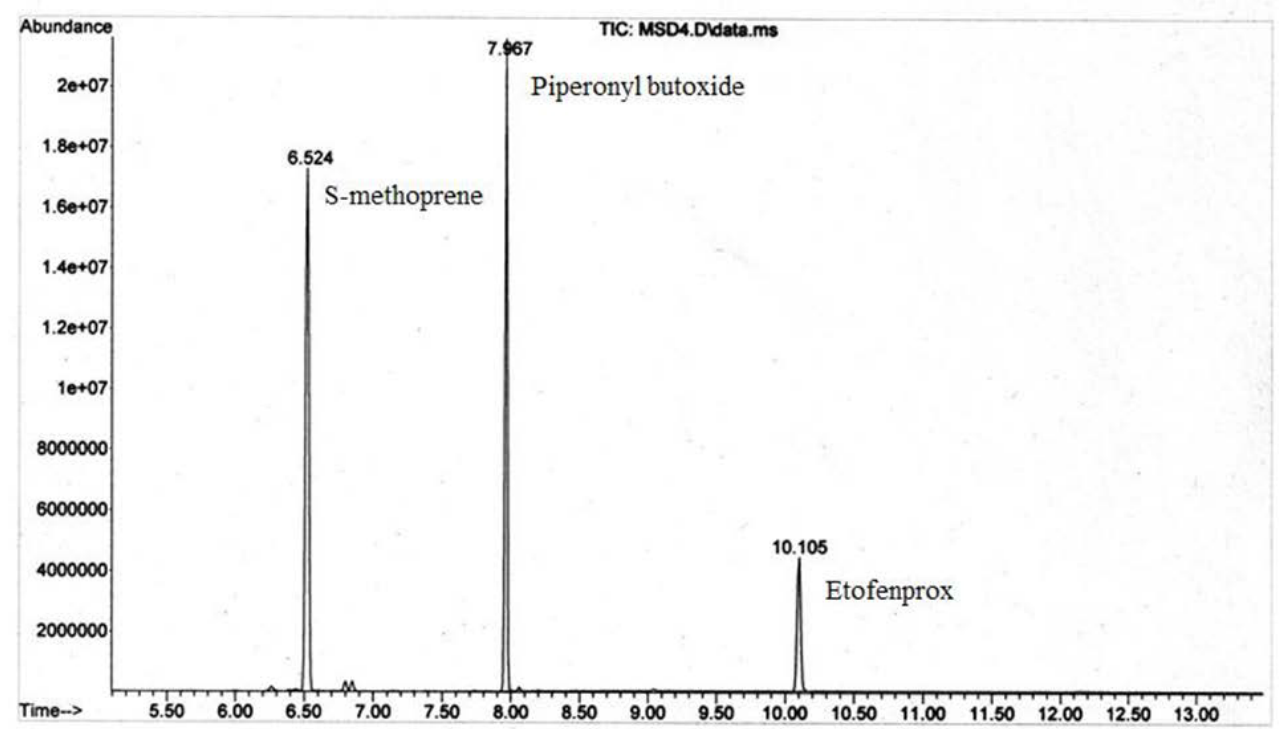

Figure 2: GC/MS-Total Ion Chromatogram (TIC) of s-methoprene (Mol. Wt., 310.47), piperonylbutoxide (Mol. Wt., 338.44), and etofenprox (Mol. Wt., 376.49). Peaks of s-methoprene, piperonylbutoxide, and etofenprox were eluted at a retention time of $6.524 \mathrm{~min}, 7.967 \mathrm{~min}$, and $10.105 \mathrm{~min}$, respectively. For detailed GC/MS conditions, see the text.

\section{Etofenprox Concentration in Gloves}

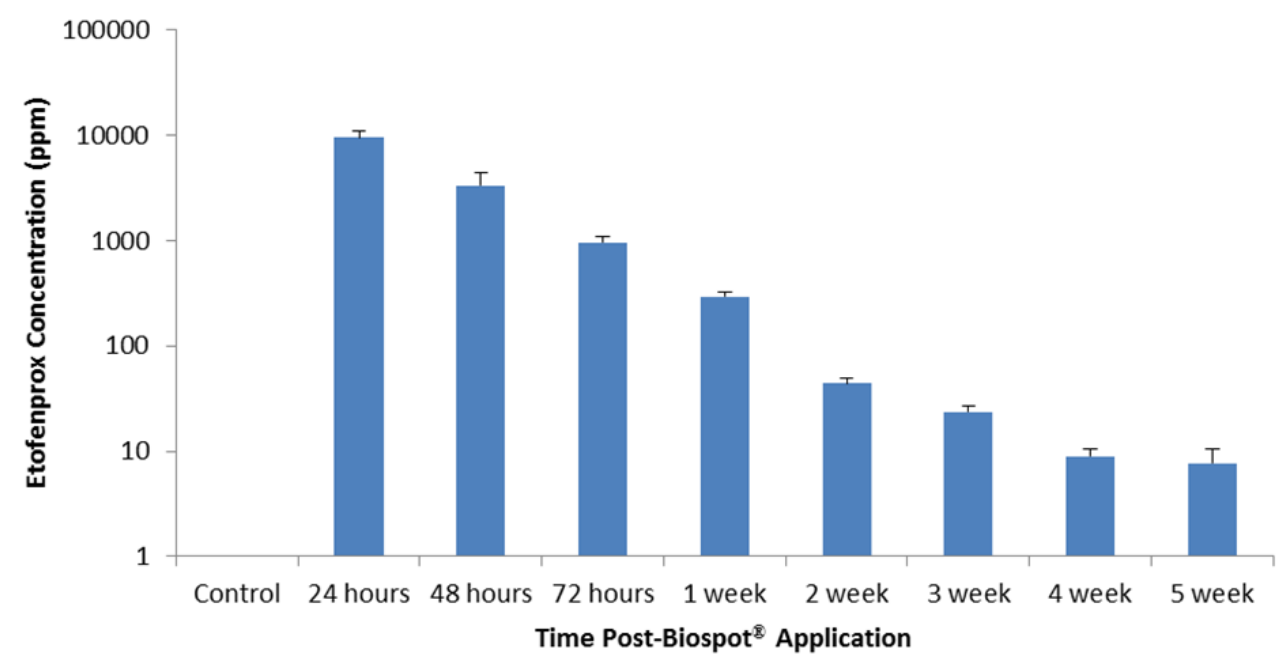

Figure 3: Concentrations of etofenprox $(\mathrm{ppm})$ in gloves (Mean $\pm \mathrm{SEM} ; \mathrm{n}=6)$. 


\section{S-methoprene Concentration in Gloves}

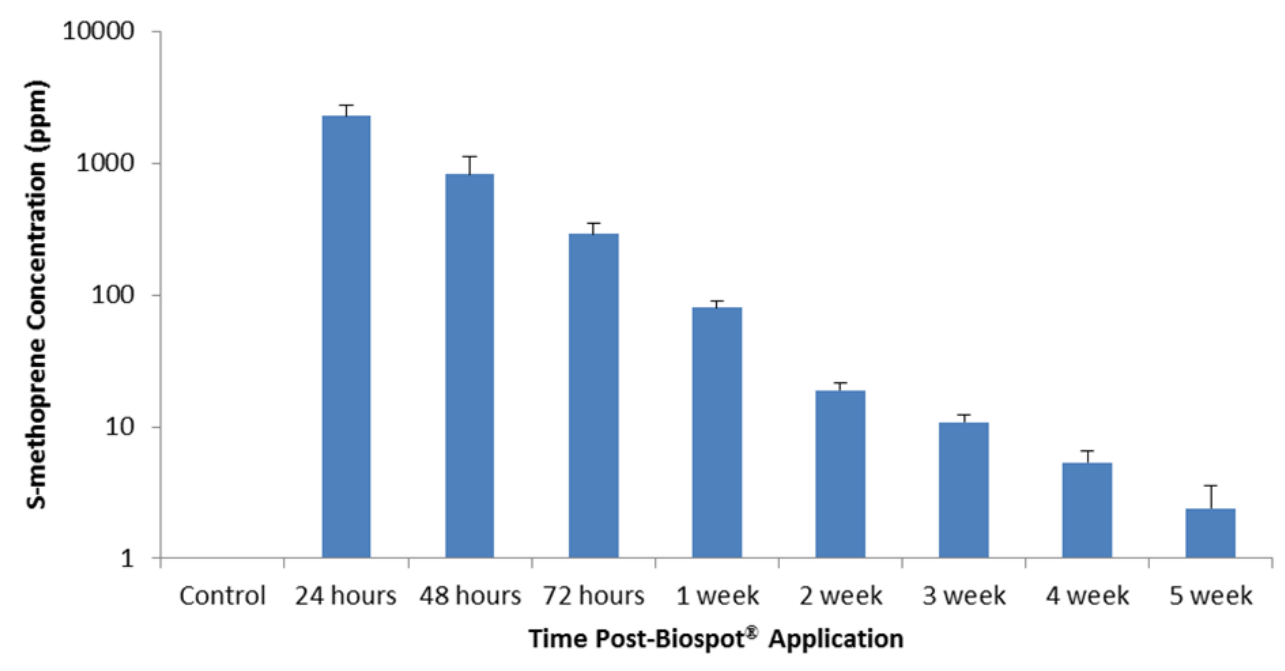

Figure 4: Concentrations of s-methoprene (ppm) in gloves (Mean \pm SEM; $n=6)$.

\section{Piperonyl butoxide Concentration in Gloves}

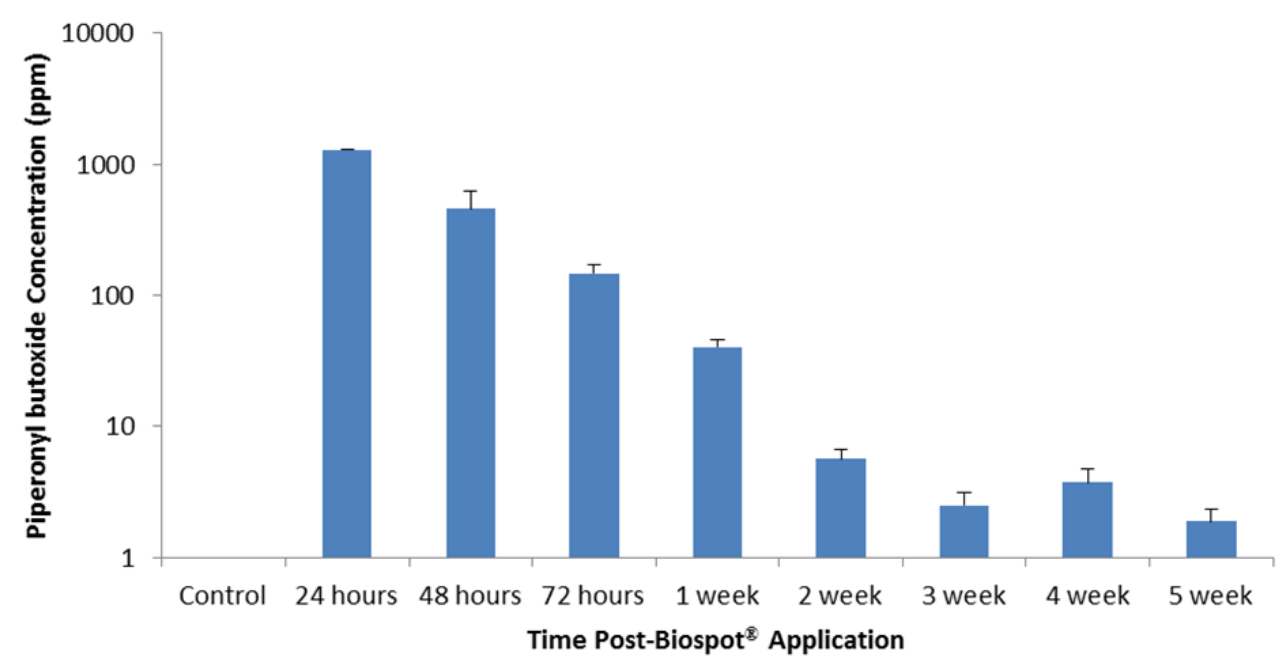

Figure 5: Concentrations of piperonylbutoxide $(\mathrm{ppm})$ in gloves (Mean $\pm \mathrm{SEM} ; \mathrm{n}=6)$.

Thereafter, with a steep decline trend, residues of these pesticides were present on the canine coat until five weeks post-application of Bio Spot Defense.

Dog blood analysis for pesticide residues revealed the presence of only etofenprox (Figure 6). Its highest concentration was detected after 48 hours $(18.42 \pm 5.05 \mu \mathrm{g} / \mathrm{g})$. By 72 hours, etofenprox concentration reduced to $1.22 \pm 0.42 \mu \mathrm{g} / \mathrm{g}$, and after one week, the level was $0.80 \pm 0.35$ $\mu \mathrm{g} / \mathrm{g}$. Thereafter, etofenprox residue was undetectable in blood. At no time was residue of either s-methoprene or piperonyl butoxide detected in the dog blood.

\section{Discussion}

The present investigation was carried out in response to common queries of veterinarians about the safety of Bio Spot Defense to dogs and veterinary personnel. Although literature abounds showing the basic toxicity data of etofenprox, s-methoprene, and piperonyl butoxide (major ingredients in Bio Spot Defense) in rats and mice, no reports are there to support the safety of this product with regards to dogs, dog owners, or veterinary personnel. This study was therefore done in an attempt to simulate exposure of veterinary personnel to transferrable residue of etofenprox, s-methoprene, and piperonyl butoxide from the coat of dogs treated with Bio Spot Defense.

Based on types of symptoms and syndromes produced, pyrethroids are categorized into two types: (a) type I that lack cyano group termed as T (tremors), e.g., permethrin; and type II that contain cyano group termed as CS (choreoathetosis/salivation), e.g. deltamethrin $[2,14,17$ 19]. Pyrethroids are neurotoxicants $[20,21]$ and primarily affect the sodium channel of cells, but chloride and calcium channels are also 


\section{Etofenprox Concentration in Canine Blood}

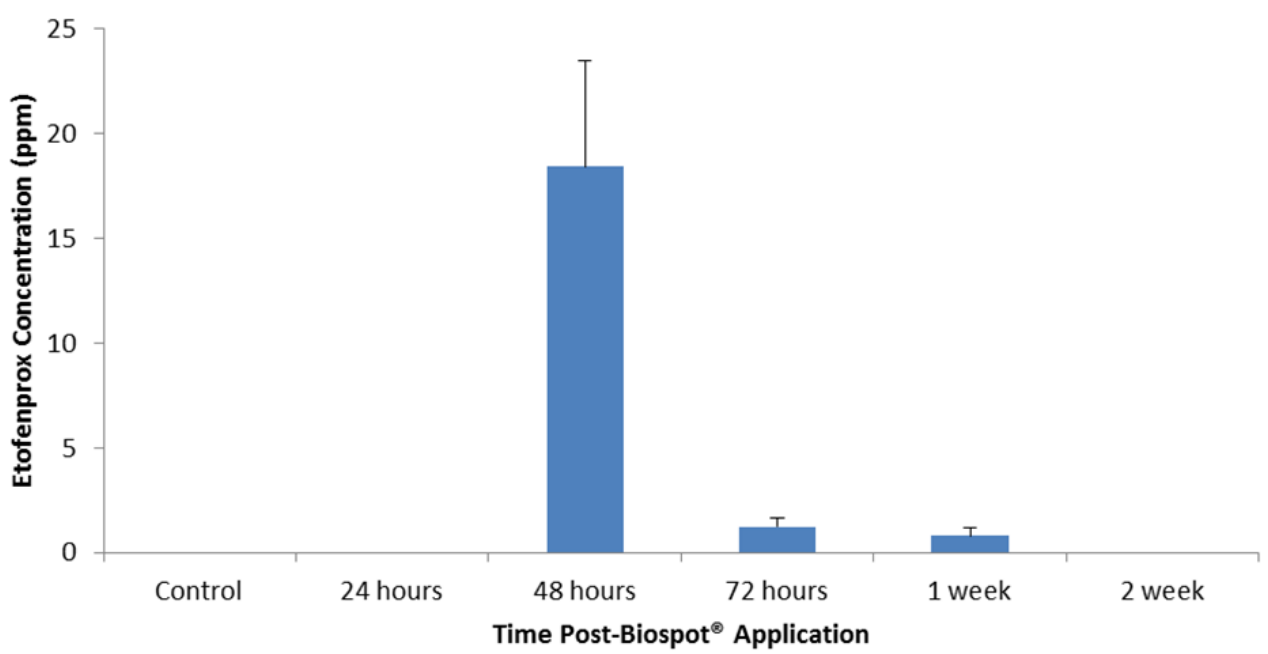

Figure 6: Concentration of etofenprox in dog blood (Mean \pm SEM; $n=6$ ).

affected [18,22-24]. Pyrethrins and pyrethroids slow the opening and closing of the sodium channels, resulting in excitation of the cells $[25,26]$. The duration of the sodium action potential is much longer for type II pyrethroids than for type I. Paresthesia results from the direct action of pyrethroids on sensory nerve endings, causing repetitive firing of these fibers. There is marked stereospecificity of the action of pyrethroids on the sodium channel, i.e. the cis isomers are usually more toxic than trans isomers $[27,28]$. It is noteworthy that unlike the other pyrethrins and pyrethroids, etofenprox is a non-ester pyrethroid, which does not contain a cyano group and centers of molecular asymmetry and therefore does not show stereoisomerism.

In dogs, toxic reactions to pyrethroids include itching and allergic reactions (paw flicking, ear twitching, and respiratory distress), and hypersalivation, that can eventually progress to diarrhea, in coordination, depression and muscle tremors. Clinical signs associated with pyrethroid exposure are usually resolved within 24 to 72 hours. Death occurs in dogs in rare cases [2]. The American Association of Poison Control Centers reported more than 20,000 pyrethroid exposures in humans in 2006 [29]. In humans, the symptoms that may arise from acute oral exposure to pyrethroids include dizziness, headache, nausea, anorexia, fatigue, vomiting, mild disturbance of consciousness, or muscle fasciculations in limbs [30]. It is rare for an individual to die from pyrethroid poisoning, although pulmonary edema, convulsions and coma have been recorded following exposure to high concentrations of pyrethroids. The signs of overt dermal exposure to pyrethroids in humans include burning, itching or tingling sensation of the skin [30]. In the present investigation in dogs, in spite of significant amounts of etofenprox, s-methoprene and piperonyl butoxide present on canines' coats, and etofenprox in the blood after Bio Spot Defense application, at no time did any canine show any behavioral abnormality or dermal reaction at the site of application.

In the present study, residues of etofenprox, s-methoprene, and piperonyl butoxide on dog's coat appeared to be within safe limits following dermal application of Bio Spot Defense. Currently, dogs and cats with pyrethrins and pyrethroids poisoning often seen in veterinary clinics and confirmed at the diagnostic centers might be due to oral ingestion of products having pyrethrins and pyrethroids meant for dermal application.

There are some reports on pharmacokinetic and PBPK values of some pyrethroids [31-33], but very little is known about etofenprox. A wide species and age-dependent variation appears to exist in pharmacokinetics and susceptibility to pyrethroid toxicity [31,34-37]. The absorption of pyrethroids in mammals through the skin is very low and it is lesser in humans than in animals [37-39], but following oral administration it appears to be consistently 40-60\% [14]. Hawkins et al. [40] reported that following oral administration of etofenprox $(30 \mathrm{mg} / \mathrm{kg}$ or $180 \mathrm{mg} / \mathrm{kg}$ ) in rats, its bioavailability was about $14-51 \%$, and the residue was detected in blood (5-16 ppm), liver (0.34 ppm), fat $(16.6 \mathrm{ppm})$, and brain $(0.002-0.004 \mathrm{ppm})$. Phase I metabolites of etofenprox include desethyletofenprox, 4'-hydroxyetofenprox, a-CO (2-(4-ethoxyphenyl)-2-methyl propyl-3-phenoxybenzoate), ethoxyphenyl-2-methylpropanol, 3-phenoxybenzoic acid, and 4'-OH3-phenoxybenzoic acid; and phase II metabolites include glucuronide and sulfate conjugates of oxidation products $[14,41,42]$. Hawkins et al. [40] also indicated that etofenprox was eliminated $8-10.8 \%$ in the urine and $86.4-88 \%$ in the feces.

Peak blood/plasma and brain concentrations of pyrethroids tend to correlate with clinical signs of neurotoxicity after acute oral dosing of a pyrethroid $[14,43,44]$. Such signs usually dissipate within hours after a single gavage dosing, correlating with the reduction in blood/ plasma pyrethroid concentration. In the present investigation, after 48 hours of Bio Spot Defense application, the concentration of etofenprox in the blood was $18.42 \mu \mathrm{g} / \mathrm{g}$, which was 180 times less than that found on the coat $(3333.43 \mu \mathrm{g} / \mathrm{g})$. Lack of s-methoprene or piperonyl butoxide in the dog blood appears to be due to their inability to dermal penetration.

Veterinarians and veterinary technicians handle a large number of canine patients every day. Therefore, it is important to assess the levels of transferrable residue of etofenprox, (s)-methoprene, and piperonyl butoxide from treated dogs to veterinary personnel. Currently, there are no published studies regarding the effects of these pesticides on human health from Bio Spot Defense use on dogs. In previous studies, we reported the transferrable residue of fipronil from Frontline ${ }^{\mathrm{nt}}$ [9], 
Citation: Bland SD, Gupta RC, Lasher MA, Canerdy TD (2013) Safety Assessment of Etofenprox, S-Methoprene, and Piperonyl Butoxide in Dogs Topically Exposed to Bio Spot Defense. J Veterinar Sci Technol 4: 148. doi:10.4172/2157-7579.1000148

Page 6 of 7

imidacloprid from Advantage ${ }^{\oplus}$ [10], and selamectin from Revolution ${ }^{\text {rm }}$ $[11,12]$ treated dogs. Dogs treated with Advantage and Revolution ${ }^{\text {tw }}$ also had in their blood significant residue of imidacloprid and selamectin, respectively, for several days post-treatment. The present study demonstrated that levels of etofenprox, s-methoprene, and piperonyl butoxide on the canine coat could be transferred to human skin surfaces directly or through glove contamination.

\section{Conclusions}

This investigation was undertaken to assess the safety and toxicity of Bio Spot Defense in dogs, and related health concerns to humans. Findings revealed the persistence of etofenprox, s-methoprene, and piperonyl butoxide residues on the canine's coat in significant amounts that can be transferred to humans through their contact with the dogs. The levels of these pesticides on the dogs coat were highest at 24 hours post-application, which can be the time of greatest risk to human exposure. After 1 week, the concentrations rapidly declined, yet insignificant levels were present until week five. Etofenprox level in the dogs' blood was highest at 48 hours, and persisted until 1 week. At no time was s-methoprene or piperonyl butoxide detected in the dog blood. Bio Spot Defense was found to be safe for topical application, as none of the dogs showed any adverse effects, and no skin reactions occurred at the application site. Veterinarians, veterinary technologists, and dog handlers can be exposed to significant levels of ectoparasiticides following chronic exposure, being in close contact with treated dogs, if not properly protected.

\section{References}

1. Anadón A, Martínez-Larrañaga MR, Martínez MA (2009) Use and abuse of pyrethrins and synthetic pyrethroids in veterinary medicine. Vet J 182: 7-20.

2. Ensley SM (2012) Pyrethrins and pyrethroids. In: Gupta RC(Ed) (2012) Veterinary Toxicology: Basic and Clinical Principles. (2 ${ }^{\text {nd }}$ Edn) Academic Press Elsevier, Amsterdam.

3. Bio Spot Defense Flea Control for Dogs. 1-800-PetMeds. PetMed Express, Web. 24 Apr 2013

4. Bio Spot (2013) Farnam Companies, Web. 24 Apr 2013.

5. EPA (2001) Methoprene. Pesticide fact sheet.

6. Methoprene (2012) National Pesticide Information Center. Web. May 3, 2013.

7. PiperonylButoxide (2000) NPIC. Web 8 May 2013.

8. Etofenprox, Pesticide Tolerance (2008) Federal Register73(240).

9. Jennings KA, Canerdy TD, Keller RJ, Atieh BH, Doss RB, et al. (2002) Human exposure to fipronil from dogs treated with frontline. Vet Hum Toxicol 44: $301-$ 303

10. Craig MS, Gupta RC, Candery TD, Britton DA (2005) Human exposure to imidacloprid from dogs treated with advantage(r). Toxicol Mech Methods 15: 287-291.

11. Gupta RC, Masthay MB, Canerdy TD, Acosta TM, Provost RJ, et al. (2005) Human exposure to selamectin from dogs treated with revolution: methodological consideration for selamectin isolation. Toxicol Mech Methods 15: 317-321.

12. Gupta RC (2007) Ivermectin and selamectin. In: Gupta RC (2012) Veterinary Toxicology: Basic and Clinical Principles. Academic Press/Elsevier, Amsterdam.

13. Wright JE (1976) Environmental and toxicological aspects of insect growth regulators. Environ Health Perspect 14: 127-132.

14. Gammon DK, Chandrasekaran A, EINaggar SF (2012) Comparative metabolism and toxicology of pyrethroids in mammals. In: Marrs TC (2012) Mammalian Toxicology of Insecticides. RSC Publishing, Cambridge, UK.

15. Marrs TC (2012) Insecticides that interfere with insect growth and development. In: Marrs TC (Ed) Mammalian Toxicology of Insecticides. RSC Publishing, Cambridge, UK.
16. Woodward KN (2012) Veterinary pesticides. In: Marrs TC (2012) Mammalian Toxicology of Insecticides. RSC Publishing, Cambridge, UK.

17. Lawrence LJ, Casida JE (1982) Pyrethroid toxicology: mouse intracerebral structure-activity relationships. Pest BiochemPhysiol 18: 9-14.

18. Ray DE, Forshaw PJ (2000) Pyrethroid insecticides: poisoning syndromes, synergies, and therapy. J Toxicol Clin Toxicol 38: 95-101.

19. Ray DE (2001) Pyrethroid insecticides: mechanisms of toxicity, systemic poisoning syndromes, paresthesia and therapy. In Hayes' Handbook of Pesticide Toxicology. Elsevier, London, UK.

20. Wolansky MJ, Harrill JA (2008) Neurobehavioral toxicology of pyrethroid insecticides in adult animals: a critical review. Neurotoxicol Teratol 30: 55-78.

21. vanThriel C, Hengstler JG, Marchan R (2012) Pyrethroid insecticide neurotoxicity. Arch Toxicol 86: 341-342.

22. Soderlund DM, Clark JM, Sheets LP, Mullin LS, Piccirillo VJ, et al. (2002) Mechanisms of pyrethroid neurotoxicity: implications for cumulative risk assessment. Toxicology 171: 3-59.

23. Shafer TJ, Meyer DA (2004) Effects of pyrethroids on voltage-sensitive calcium channels: a critical evaluation of strengths, weaknesses, data needs, and relationship to assessment of cumulative neurotoxicity. Toxicol Appl Pharmacol 196: 303-318.

24. Ray DE, Fry JR (2006) A reassessment of the neurotoxicity of pyrethroid insecticides. Pharmacol Ther 111: 174-193.

25. Marban E, Yamagishi T, Tomaselli GF (1998) Structure and function of voltagegated sodium channels. J Physiol 508: 647-657.

26. Conley EC, Brammar WJ (1999) The Ion Channel Facts Book. Academic Press, San Diego, CA

27. Meacham CA, Brodfuehrer PD, Watkins JA, Shafer TJ (2008) Developmentallyregulated sodium channel subunits are differentially sensitive to alpha-cyano containing pyrethroids. Toxicol Appl Pharmacol 231: 273-281.

28. Soderlund DM (2012) Molecular mechanisms of pyrethroid insecticide neurotoxicity: recent advances. Arch Toxicol 86: 165-181.

29. Bronstein AC, Spyker DA, Cantilena LR Jr, Green J, Rumack BH, et al. (2007) 2006 Annual Report of the American Association of Poison Control Centers' National Poison Data System (NPDS). Clin Toxicol (Phila) 45: 815-917.

30. He F, Wang S, Liu L, Chen S, Zhang Z, et al. (1989) Clinical manifestations and diagnosis of acute pyrethroid poisoning. Arch Toxicol 63: 54-58.

31. Godin SJ, Scollon EJ, Hughes MF, Potter PM, DeVito MJ, et al. (2006) Species differences in the in vitro metabolism of deltamethrin and esfenvalerate: differential oxidative and hydrolytic metabolism by humans and rats. Drug Metab Dispos 34: 1764-1771.

32. Mirfazaelian A, Kim KB, Anand SS, Kim HJ, Tornero-Velez R, et al. (2006) Development of a physiologically based pharmacokinetic model for deltamethrin in the adult male Sprague-Dawley rat. Toxicol Sci 93: 432-442.

33. Crow JA, Borazjani A, Potter PM, Ross MK (2007) Hydrolysis of pyrethroids by human and rat tissues: examination of intestinal, liver and serum carboxylesterases. Toxicol Appl Pharmacol 221: 1-12.

34. Sheets LP, Doherty JD, Law MW, Reiter LW, Crofton KM (1994) Age-dependent differences in the susceptibility of rats to deltamethrin. Toxicol Appl Pharmaco 126: $186-190$.

35. Anadón A, Martinez-Larrañaga MR, Fernandez-Cruz ML, Diaz MJ, Fernandez MC, et al. (1996) Toxicokinetics of deltamethrin and its 4'-HO-metabolite in the rat. Toxicol Appl Pharmacol 141: 8-16.

36. Sidon EW, Moody RP, Franklin CA (1988) Percutaneous absorption of cis- and trans-permethrin in rhesus monkeys and rats: anatomic site and interspecies variation. J Toxicol Environ Health 23: 207-216.

37. Hughes MF, Edwards BC (2010) In vitro dermal absorption of pyrethroid pesticides in human and rat skin. Toxicol Appl Pharmacol 246: 29-37.

38. Franz TJ, Lehman PA, Franz SF, Guin JD (1996) Comparative percutaneous absorption of lindane and permethrin. Arch Dermatol 132: 901-905.

39. Tomalik-Scharte D, Lazar A, Meins J, Bastian B, Ihrig M, et al. (2005) Derma absorption of permethrin following topical administration. Eur $\mathrm{J}$ Clin Pharmacol 61: 399-404. 
Citation: Bland SD, Gupta RC, Lasher MA, Canerdy TD (2013) Safety Assessment of Etofenprox, S-Methoprene, and Piperonyl Butoxide in Dogs Topically Exposed to Bio Spot Defense. J Veterinar Sci Technol 4: 148. doi:10.4172/2157-7579.1000148

40. Hawkins DR, Kilpatrick D, Eween B, Midgley I, Biggs SR, Whithy BR (1985) The biokinetics and metabolism of $14 \mathrm{C}$-etofenprox in the rat. Report numbe HRC/MTC 68/8610. Huntington Research Centre, England. Submitted to WHO by Mitsui Toatsu Chemicals, Inc, Tokyo, Japan.

41. Kaneko H (2010) Pyrethroid chemistry and metabolism. In Hayes' Handbook of Pesticide Toxicology. Elsevier, London, UK.

42. Kaneko H (2011) Pyrethroids: mammalian metabolism and toxicity. J Agric Food Chem 59: 2786-2791.
43. White INH, Verschoyle RD, Moradian MH, Barnes JM (1976) The relationship between brain levels of cismethrin and bioresmethrin in female rats and neurotoxic effects. Pest Biochem Physiol 6: 491-500.

44. Rickard J, Brodie ME (1985) Correlation of blood and brain levels of the neurotoxic pyrethroiddeltamethrin with the onset of symptoms in rats. Pest Biochem Physiol 23:143-156. 